\title{
Las relaciones transnacionales de solidaridad con los movimientos revolucionarios latinoamericanos durante la guerra fría. Introducción
}

\section{Transnational Solidarity Relations with Latin American Revolutionary Movements during the Cold War. Introduction}

\author{
José Manuel Ágreda Portero \\ (D) https://orcid.org/0000-0001-8503-0927 \\ Universidad de Santiago de Compostela, España \\ josemanuel.agreda@rai.usc.es
}

\section{Friederike Apelt}

(D) https://orcid.org/0000-0001-9311-4143

Universidad de Hannover, Alemania

f.apelt@posteo.de

Resumen: Los movimientos revolucionarios latinoamericanos que emergieron desde los años cincuenta crearon redes transnacionales de solidaridad para con su causa. El presente dossier expone investigaciones que pretenden avanzar en su

cómo citAR: Ágreda Portero, J. M. y Apelt, F. (2020). Las relaciones transnacionales de solidaridad con los movimientos revolucionarios latinoamericanos durante la guerra fría. Introducción. Secuencia (108), e1905. DOI: https://doi.org/10.18234/secuencia.v0i108.1905 
conocimiento. A partir de un planteamiento común se propone el estudio desde amplios y variados parámetros: cultura, género, política, derechos humanos o sociedad civil global, entre otros. En resumen, se exponen los trabajos de doce investigadores que, teniendo como contexto global la guerra fría, intentan comprender las relaciones entre los movimientos revolucionarios y diferentes actores que se movilizaron en solidaridad. Además, para ampliar la perspectiva, el dossier también incluye una contribución fuera de cartel sobre las relaciones entre la solidaridad holandesa y portuguesa en apoyo de las independencias africanas.

Palabras clave: solidaridad; red transnacional; movimientos revolucionarios; América Latina; guerra fría.

Abstract: The Latin American revolutionary movements that emerged in the 1950s created transnational solidarity network to promote their cause. This dossier presents research seeking to advance knowledge of this issue. Based on a common approach, it studies these movements and networks from broad and varied parameters, such as culture, gender, politics, human rights, and global civil society. In short, it presents the work of twelve researchers who, against the backdrop of the Cold War, attempt to understand the relationships between the revolutionary movements and the various actors who mobilized in solidarity. In addition, to broaden the perspective, the dossier also includes a special contribution on relations between Dutch and Portuguese solidarity in support of African independence movements.

Key words: solidarity; transnational network; revolutionary movements; Latin America; cold war.

Silvio Rodríguez publicó en el año 1982 el disco Unicornio, entre sus poemas Se hallaba Canción urgente para Nicaragua:

Se partió en Nicaragua otro hierro caliente [se repite]

Con que el águila daba su señal a la gente [se repite]

Se partió en Nicaragua 


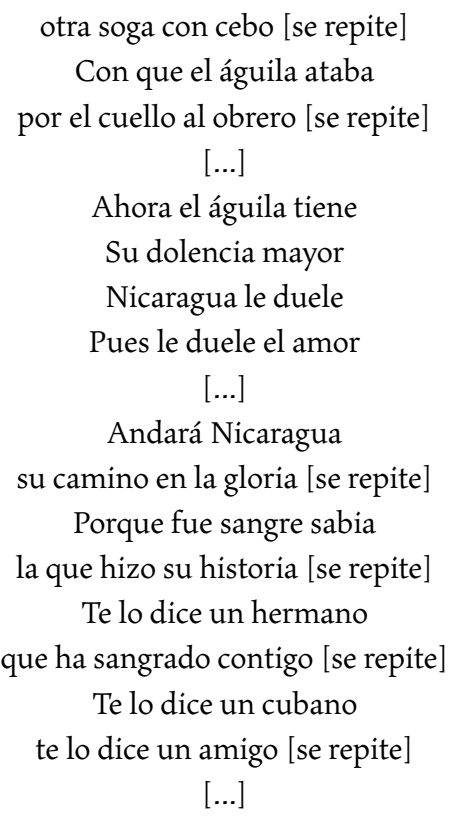

Un año más tarde, en abril de 1983, pudo interpretarla en la propia Managua dentro del marco del festival de música sobre la nueva canción latinoamericana. ${ }^{1}$ Junto con otros artistas, como los hermanos nicaragüenses Luis Enrique y Carlos Mejía Godoy o Mercedes Sosa, publicaron un disco en directo que fue distribuido por todo el mundo. El concierto fue grabado gracias a la participación de la solidaridad con Nicaragua en Holanda. Hans Langenberg, miembro del comité, acordó con tres productoras holandesas su grabación y distribución. Además, se tenía apalabrada la emisión en la televisión griega y se estaba pendiente del acuerdo con la alemana. ${ }^{2}$

El festival de Managua acogió asistentes de todos los países con participación en la red de solidaridad que se había conformado ya antes del triunfo de la revolución el 19 de julio de 1979. Los activistas de la solidaridad difundieron su entusiasmo, información y el espíritu revolucionario en sus países

${ }^{1}$ Cantos en abril para la paz. Barricada Internacional, 28 de marzo de 1983, p. 12.

${ }^{2}$ Un canto por la paz. II Festival de la Nueva Canción. Barricada Internacional, 25 de abril de 1983, p. 8 . 
de origen. Uno de los objetivos fue el reclutamiento de nuevos miembros que apoyasen las labores solidarias.

Este no fue un hecho aislado, tanto en Europa como en América se realizaron creaciones artísticas de apoyo a la revolución sandinista y otros territorios centroamericanos. Por ejemplo, el grupo The Clash publicó un triple disco en 1980 con el nombre Sandinista. Aunque no crearon ninguna canción específica sobre Nicaragua, si se puede encontrar en el álbum el corte Washington bullets donde se denuncia la intervención estadunidense en Chile, Cuba o Nicaragua. Otros autores fueron el canadiense Bruce Cockburn con el tema Nicaragua en 1984, el grupo vasco Kortatu con la canción Nicaragua, jsandinista!, en 1985 o el italiano Gaetano Liguori que en 1988 publicó un disco de jazz titulado ; Que viva Nicaragua!

La música desarrolló un papel importante en las redes de solidaridad con los movimientos revolucionarios durante las décadas de los años sesenta, setenta y ochenta. Como expresan Martín y Rey (2012, p. 3) para América Latina, o Lee Anderson (2018) también para África y Asia, existió un ethos revolucionario común que transcendió más allá de fronteras y creó vínculos emocionales con los distintos grupos guerrilleros encontrando una amplia expresión en la cultura. También lo hizo con los grupos que apoyaron estas luchas.

Este es sólo un ejemplo de cómo las redes solidaridad fueron un hecho importante en los conflictos acaecidos durante la guerra fría que es necesario investigar. El objetivo principal de este dossier es analizar el proceso transnacional de solidaridad con los movimientos revolucionarios latinoamericanos desde cualquier punto del planeta. La idea fue originada en el panel "Relaciones solidarias transnacionales con los movimientos revolucionarios latinoamericanos durante la guerra fría" que tuvo lugar en Salamanca, dentro del marco del $56^{\circ}$ Congreso Internacional de Americanistas, durante 2018, organizado por los dos coordinadores de este dossier.

La acotación cronológica se ha marcado desde el triunfo de la revolución cubana en 1959, a partir de ella, la historiografía denomina a estos movimientos Nueva Izquierda Latinoamericana, y terminaría en el fin del conflicto armado centroamericano a mitad de la década de los noventa.

La perspectiva desde la que se ha pretendido abordar ha sido la más amplia posible: cultura, género, política, derechos humanos, sociedad civil global, violencia, movimientos sociales, etc. También, desde el punto de vista geopolítico se ha propuesto que la relación entre los demandantes de solidaridad y los que la ofrecían no estuviera marcada por las relaciones Norte-Sur, 
por ello, se abrieron las propuestas a las relaciones Sur-Norte, Sur-Sur y Norte-Norte. Las contribuciones de este dossier muestran diferentes aspectos de los complejos y enredados procesos de interacción en el contexto global de la guerra fría y sus particularidades regionales.

En los años setenta, Nye y Kehoane (1971) ya abogaron por extender los estudios sobre relaciones internacionales más allá de los clásicos estudios diplomáticos, donde los países se mueven en la arena política internacional como si fuesen unitarios. El estudio de estas redes transnacionales es una manera de romper con esta barrera monolítica y ampliar la visión de una época tan compleja como la guerra fría. Thomas Olesen (2011) expone claramente las posibilidades que ofrece: "Solidarity campaigns therefore provide a very fruitful empirical prism for studying the sociological aspects of globalization" (p. 156). Pero no sólo es un tema de globalización, sino también transnacional, en el sentido de conexiones entre poblaciones de dos países más allá de sus aparatos estatales, o de movimientos sociales en busca de justicia social, derechos humanos, etc. Todo ello suma en el conocimiento y aporta, como se ha explicado, una visión diferente y necesaria.

\section{PARTICIPANTES EN EL DOSSIER}

En la primera contribución al dossier, Grethel Domenech Hernandéz se acerca a un aspecto poco estudiado. La autora analiza la solidaridad intelectual a través de la publicación mexicana El Corno Emplumado. En ella se muestra la creación de una red intelectual transnacional durante los años sesenta. Los siguientes artículos, centrados también en el significado de la cultura como un elemento importante en la creación de solidaridad, no son menos innovadores. A través del Museo de la Solidaridad en Chile (1970-1973) y su desarrollo en el exilio como Museo de la Resistencia Salvador Allende (1975-1990), Elodie Lebeau muestra la importancia de la cultura en la creación de redes e interconexiones políticas, artísticas e intelectuales a niveles tanto local, como nacional o internacional.

Pilatowsky y Cabranes estudian las imágenes de los carteles en la solidaridad francesa entre las décadas de los setenta y ochenta. A través de ellos se puede observar la solidaridad Norte-Sur, haciendo de la cultura uno de los puntos de conexión entre sociedades tan distintas y que llevan a expresiones de arte escrito y visual. 
Señalando la importancia de la música en la expresión de solidaridad, Eileen Karmy y Natália Ayo Schmiedecke exploran la solidaridad desde y con Chile durante los años de gobierno de la Unidad Popular a través de la nueva canción chilena. Ellas muestran cómo la música sirve para resolver conflictos entre los diferentes actores o cómo profundizan en ellos. Una manera de construir la unidad dentro de la Nueva Canción fue la denuncia del imperialismo estadunidense. Desde una similar perspectiva, Juan Alberto Salazar presenta un trabajo sobre un encuentro de canción protesta y antiimperialista en Cuba durante 1967. Además, estas investigaciones se entroncan con el estudio de la solidaridad Sur-Sur.

Como Mariana Perry demuestra convincentemente en su contribución sobre la influencia de la Unidad Popular chilena en la izquierda británica, las relaciones solidarias no deben ser entendidas en una sola dirección: aquellos que ofertan la solidaridad aprenden de aquellos que están peleando. La huella que los movimientos revolucionarios latinoamericanos dejaron en la izquierda occidental todavía está en progreso de estudio.

Los derechos humanos fue un factor importante para el éxito de las redes tanto chilenas como argentinas. Los miles de asesinados y desaparecidos en los dos países fueron un reclamo importante para obtener solidaridad en muchas partes del mundo. Marianela Scocco se acerca a las narrativas que emanan del movimiento de derechos humanos en Argentina. Para la autora, estos crean una narrativa humanitaria distinta de la que desarrollaron los movimientos revolucionarios, y esto les proveyó del contacto con las redes de solidaridad.

La red de solidaridad con la revolución sandinista en Nicaragua es uno de los temas que recientemente ha ganado mayor atención, por ello en este dossier se publican varios trabajos sobre ella con aportaciones importantes.

Tanto Eudald Cortina como Gerardo Sánchez se acercan desde la visión Sur-Sur. Cortina se adentra desde el viaje que realizan un grupo de exiliados montoneros en México al Frente Sur en 1979 con una brigada médica. Además, el autor también pone atención en el acto de reciprocidad que supone la solidaridad. Por su parte, Sánchez realiza una panorámica sobre el movimiento mexicano de solidaridad con Nicaragua. Específicamente, presta atención a las relaciones de la guerrilla sandinista con el Estado, sindicatos y gobierno mexicanos, buscando en las dinámicas políticas la forma en que fueron realizadas y los múltiples intereses que tuvieron. 
Los Estados también han sido tomados en consideración con los trabajos de Fernando Camacho, sobre los regímenes de Pinochet y el Frente Sandinista de Liberación Nacional (FSLN), y Mónika Szente-Varga, sobre la relación entre Hungría y Nicaragua. Camacho se concentra en las estrategias del regimen militar chileno para prevenir que Nicaragua llegara a convertirse en un lugar central de solidaridad con la oposición chilena. En su texto hace un recorrido que se inicia con las relaciones entre los dictadores de los dos países, continua por la llegada de exiliados chilenos a Nicaragua con la intención de organizarse para derrocar a Pinochet, y finaliza con el cierre de la embajada chilena en Managua durante 1985. Mientras Szente-Varga se acerca a la dificultad que tuvo Hungría, durante los años ochenta, ya en una grave situación económica de realizar aportaciones sustanciales a la revolución sandinista. Ella expone convincentemente los conflictos de intereses entre los objetivos nacionales de Hungría y los geoestratégicos de Moscú en apoyo de Nicaragua que demanda de Hungría. Este hecho apunta a mostrar las relaciones bilaterales entre los dos países y al mismo tiempo disipar el mito de las perfectas relaciones.

José Manuel Ágreda ha trabajado sobre el papel del Estado en la red transnacional entre Nicaragua y España de 1979 a 1992. El autor ha partido de presupuestos teóricos para establecer tanto las características de la red como de los activistas españoles que participaron en ella. Esta es una aproximación más teórica que las anteriores y permite comparar las redes tanto en el periodo de la guerra fría como en el de finales del siglo xx y principios del xxI.

El último artículo es el realizado por Dirk Kruijt, quien deja Latinoamérica y amplía la perspectiva del dossier. Se acerca a la solidaridad Norte-Norte en la que desde Holanda se apoyan las luchas tanto para la independencia de las colonias portuguesas como la creación de la solidaridad en el propio Portugal. Una aportación original que desde estas líneas quiere agradecerse.

\section{LISTA DE REFERENCIAS}

Lee Anderson, J. (2018). Guerrillas. México: Editorial Sexto Piso.

Martín, A. y Rey, E. (2012). La oleada revolucionaria latinoamericana contemporánea, 1959-1996. Definición, caracterización y algunas claves para su análisis. Naveg@merica, 9. 
Nye, J. y Keohane, R. (1971). Transnational relations and world politics: an introduction. International Organization, 25(3), 329-349.

Olesen, T. (2011). The Transnational Complexity of Domestic Solidarity Campaigns: a Cross-Time Comparison of Burma Debates in Denmark, 1988 \& 2007. Acta Sociológica, 54(2), 139-159. DoI: https://doi.org/10.1177/0001699311403632 